\title{
Do we think alike? A cross-cultural study of executive functioning
}

\author{
Amit S. Kelkar $\cdot$ Monica S. Hough $\cdot$ Xiangming Fang
}

Accepted: 15 October 2013/Published online: 6 November 2013

(C) Springer-Verlag Berlin Heidelberg 2013

\begin{abstract}
The current study examined differences between Eastern and Western cultures on complex cognitive-communicative skills, verbal reasoning, and executive functioning skills. Twenty-two Indian born individuals and 20 American-born individuals completed (a) Auckland individualism-collectivism scale to provide an objective measure for culture type, (b) functional assessment of verbal reasoning and executive strategies (FAVRES) to assess cognitive-communicative functioning, and (c) four subtests from the Delis-Kaplan Executive Function System (DKEFS) to assess vital executive functions. Results indicated a significant main effect of culture, with Western participants completing the four tasks on the FAVRES more rapidly and with higher scores on the reasoning subtest. On the DKEFS, Western participants demonstrated significantly higher categorical switching capabilities and category switching accuracy in the Verbal Fluency subtest. Eastern participants were significantly faster on all subtests of Trail Making. Findings suggest differences in Eastern and Western cultures on executive functioning tasks that may be explained by analytical cognitive strategies and rule-based categorization employed by Western participants to complete reasoning and category-naming tasks. Eastern participants, however, appear to allocate holistic attentional resources to help them perform more successfully on tasks such as Trail Making which require rapid application of perceptual relationships.
\end{abstract}

Keywords Culture $\cdot$ Cognition $\cdot$ Executive functions $\cdot$ Complex-cognitive communication skills

\footnotetext{
A. S. Kelkar $(\bowtie) \cdot$ M. S. Hough $\cdot$ X. Fang

Department of Communication Sciences and Disorders, East Carolina University, Greenville, NC 27858, USA

e-mail: amitkelkar@live.com
} 


\section{Introduction}

Cultural psychologists have often asked what is meant by culture and how does culture affect cognitive processing. Specifically, culture matters to the extent that a cultural perspective provides worldly insights into supposedly universal psychological processes (Triandis 1996). Along with individual biological disposition, culture regulates how people perceive, explain, and respond to various phenomena (Triandis 1996). It develops conventions about what to pay attention to and how much to weigh the elements that are sampled. For example, people in hierarchical cultures are more likely to search their environment for clues about hierarchy than clues about aesthetics (Braver and Barch 2002; Park and Gutchess 2002). Cognitive scientists have associated culture with an intricate pattern of human knowledge development, belief system, and its subsequent effect on behavior. Over the years, culture has developed as an important concept in social sciences, anthropology, with recent interest in the area of cognitive neuroscience. This study attempts to identify this intricate interplay of culture, perception, and cognitive processing specific to verbal reasoning, executive functioning and complex cognitive-communicative skills in the Eastern and Western individuals.

\section{Cultural impact on individualism and collectivism}

A basic assumption of cognitive science is that human beings from all cultures and ethnicities rely upon the same neural architectural foundation that has evolved over years, but that an individual's life experiences may shape the contents of this basic structure (Chua et al. 2005b; Goh and Park 2005). Social neuroscientists use comparison of Eastern and Western culture as popular division of differentiating cultures. Triandis (1989) argued that people in individualist cultures, such as those of North and Western Europe and North America sample, with high probability, elements of the personal self (e.g., "I am kind"). He defines individualist societies as a group of people who prefer autonomy and are independent from their in-groups. They give priority to their personal goals over the goals of their in-groups and behave primarily on the basis of their personal attitudes rather than the norms of their in-groups (Triandis 2001). People from collectivist cultures, such as those of Asia, Africa, and South America, tend to sample elements of the collective self (e.g., "my family thinks I am kind"). In collectivist cultures, people are interdependent within their in-groups (family, community, country etc.). They give priority to the goals of their in-groups and shape their own behaviors primarily on the basis of in-group norms by behaving in a communal way (Markus and Kitayama 1991; Ohbuchi et al. 1999; Oyserman and Lee 2008; Triandis 2001). Using neuroimaging techniques researchers have confirmed that these cultural values not only regulate behavior, but also modulate neural activity at the cortical level. Individuals from individualistic cultures have larger cortical areas assigned for selfrepresentation as compared to collectivistic cultures (Chiao et al. 2009; Zhu et al. 2007). These developments in brain-imaging techniques and theoretical understandings of culture, cognition, and behavior have expanded the scientific knowledge of how culture affects cognitive processing. A comparison of this 
nature has provided cultural psychologists and cognitive neuroscientists a common platform to understand the nuances of cultural influence on cognitive and information processing.

Cultural influence on cognitive processing: memory and attention

A pioneering study by Masuda and Nisbett (2001) reported cultural differences in memory for contextual details, with individuals of East Asian background recalling more information about background elements in visual stimuli compared to Americans. Although the two cultures did not differ in memory measures for central target objects, East Asians individuals were less accurate than Americans at recognizing the object when the background behind the target object was changed or removed. The authors suggested that Eastern cultures might bind objects to contexts more readily than Western cultures, due to actual cultural differences in the emphasis placed on social contexts. Apart from memory, the exploration of crosscultural differences in the organization of semantic information by categories versus similarities or relationships shows that Americans exhibit a preference for sorting by categories whereas East Asians prefer to sort by similarities and relationships (Gutchess et al. 2006; Ji et al. 2000; Unsworth et al. 2005). The organization of semantic information is greatly shaped by culture-specific learning and experiences, and that the contents of semantic memory differ across cultures (Yoon et al. 2004).

Another area of cognition that has received interest for its possible ramifications through cultural influence is attention. Attentional processes guide all human interactions with the world and robustly influence aspects of the environment to which humans orient themselves and allow the stimuli an entry into the memory systems. From the perspective of cognitive psychology, attention acts as the gateway to internal representations of external stimuli. Existing cross-cultural theories suggest that cultural differences originate because fundamental psychological differences tend to predominate across cultures. For example, individuals from Western cultures tend to focus on stimuli that are object-based, categorically related, or self-relevant whereas people from Eastern cultures tend to focus more on contextual details, similarities, and group relevant information (Chua et al. 2005a, b; Hedden et al. 2008; Masuda and Nisbett 2001). Attentional differences are evident even at the emotional level where Asians have been found to pay more attention to others "emotional" status and context as they believe that one's behavior is influenced more by context rather than one's disposition (Nisbett 2003).

A classic example of how cultural differences emerge relative to interaction of attention and memory is evidenced in the study by Masuda and Nisbett (2001) in which they investigated the manner in which Westerners and East Asians attend to complex visual displays. American and Japanese students viewed animated vignettes of underwater scenes and reported the contents of each vignette immediately and after a time delay. Both groups demonstrated no significant difference in immediate recall. However, cultural differences originated when Japanese students reported noticeably more information about the background and their relationships to focal objects than the American students. The researchers interpreted their findings as evidence that East Asians are more attentive to context 
and relationships than Westerners. One particularly surprising finding that has emerged from research in the areas of attention is that cultural ideas and practices appear to influence even processes that are seemingly universal, including processes related to perceptual, attentional, and mnemonic representations (Duffy and Kitayama 2007; Hedden et al. 2008; Masuda and Nisbett 2001). Cultural differences relative to relationships with others in society impact the concept of self, with East Asians defining the self in terms of social obligations and network in an interdependent manner, whereas Westerners see the self as unique and separate from others in an independent manner (Chiao et al. 2009; Markus and Kitayama 1991; Zhu et al. 2007). Attention is likely to be a central process through which cultural variation may have its impact on other areas of cognition. However, an area of cognition that has been overlooked in the area of social neuroscience is executive functions and its impact of culture. The following section defines executive functions and describes the need of understanding cultural influence on this higher level cognitive skill.

\section{Cultural influence on executive functioning}

"Executive functions" is an overall term for functions such as planning, working memory, inhibition, mental flexibility, as well as the initiation and monitoring of action. Ardila (2008) discusses the evolutionary origins of executive functions and divides executive functions into two distinct concepts: "metacognitive executive functions" that include problem solving, abstraction, planning, strategy development and implementation, and working memory as well as "emotional/motivational executive functions" that are responsible for coordinating cognition and emotion. These two theoretical concepts provide an explanation for how human beings address the ability to fulfill basic impulses following socially acceptable strategies. Emotional executive functions that control and recognize what is most important in a particular situation do not necessarily include what the best conceptual and intellectual result, but what is in accordance with personal impulses (Bechara et al. 2000). Following socially acceptable strategies actually involves inhibition of selfish or unsociable basic impulses, but not necessarily arriving at the best conceptual solution. This function is related with "inhibitory control" of behavior. Previous sections described the effect of culture on memory and attention; however, there is a dearth of literature that directly compares cultural groups on their executive functioning based solely on their individualistic-collectivistic background.

The purpose of this study is to identify potential differences in individuals from individualistic and collectivistic cultures on executive functioning tasks. Positive findings from this study may identify specific aspects of executive functioning systems that are culture-dependent. Such findings would be highly beneficial for designing and creating culturally sensitive diagnostic tests for assessing cognitive skills in individuals. Most diagnostic test batteries are standardized on the population of the nation in which they are created. Consequently, aspects of tests that are exclusive to a particular culture may not be specific to individuals from other cultural populations. Creating a test that is culturally sensitive may aid in 
identifying the affected cognitive domains at a deeper level while controlling for the culture effect and increasing the internal validity of the diagnostic test. The research questions that were explored through this study are as follows (1) when measuring complex cognitive-communicative skills, is there a significant difference between individuals of two cultures (Eastern-Western)? (2) When measuring verbal reasoning skills, is there a significant difference between individuals of two cultures (Eastern-Western)? And (3) when measuring executive functioning skills, is there a significant difference between individuals of two cultures (EasternWestern)?

\section{Method}

Participants

Forty-two participants between the ages of 18-40 years (mean age 25.4 years) were recruited for the study. Twenty-two individuals (6 males and 16 females) born and raised in the United States (representative of a Western, individualistic cultural population) and twenty participants (10 males, 10 females) born and raised in Asia (all from Indian-origin), but currently residing in United States (for less than 5 years and representing an Eastern, collectivistic culture) participated in the study. It was essential that individuals from the Asian population be exposed to American culture for less than 5 years in order to decrease the effect of language and time and place of cultural exposure (Triandis 1995). All participants participated in the study on a volunteer basis and had an education level higher than a high-school degree. Each participant was assigned a value from 1 to 5 where numbers 1 to 4 corresponded to the number of years in college and 5 corresponded to completed postgraduate degree. Consistent with the ECU Institutional Review Board, each participant was fully informed of all procedures and asked to sign a consent form. The ECU Institutional Review Board approved the procedures for this study. None of the participants had a history of speech, language or cognitive problems. One participant had a history of bilateral moderate hearing loss but hearing was corrected with the use of bilateral insidethe-ear (ITE) hearing aids. Demographic information pertaining to the participants of the two cultures is shown in Table 1.

Table 1 Descriptive demographic and statistics for participants of Eastern and Western culture

\begin{tabular}{|c|c|c|c|c|c|c|c|c|}
\hline & \multicolumn{2}{|l|}{ Gender } & \multicolumn{3}{|l|}{ Age } & \multicolumn{3}{|c|}{ Education } \\
\hline & Males & Females & Mean & SD & Range & Mean & SD & Range \\
\hline Easterners & 10 & 10 & 25.00 & 2.75 & $22-33$ & 4.05 & 0.22 & $4-5$ \\
\hline Westerners & 6 & 16 & 25.77 & 6.25 & $18-40$ & 3.64 & 1.09 & $3-5$ \\
\hline
\end{tabular}


Tests

Participants completed all pre-experimental and observational testing in English. Pre-experimental testing required participants to complete the Peabody picture vocabulary test-4 (PPVT-4) (Dunn and Dunn 2007) to examine receptive vocabulary. The PPVT-4 measures understanding of the spoken word in standard American English and thus assesses vocabulary acquisition. Participant scores had to be within one standard deviation from the mean to be included in the study. Next participants completed the Auckland individualism-collectivism scale (AICS) (Shulruf et al. 2007) which provides an objective measure for culture type of participants (See Appendix). The AICS is comprised of 26 items, 11 items of which delve into collectivistic attributes of seeking advice (7 items) and maintaining harmony (4 items), and 15 items which relate to individualistic qualities of competition (7 items), being unique (4 items), and taking responsibility for one's own actions (4 items). Scores on the AICS are rated on an ordinal scale within a range of 1.0-6.0 where 1 corresponds to "Never" and 6 correspond to "Always". The scale was used to provide Individualism and Collectivism scores for every participant.

Functional assessment of verbal reasoning and executive strategies (FAVRES) was administered to assess the following aspects of cognitive-communication functioning: (a) complex comprehension; (b) complex expression; (c) verbal reasoning and problem solving; (d) executive functions (MacDonald and Johnson 2005). Participants completed four tasks: planning an event, scheduling tasks, making a decision and building a case. Each task was scored on accuracy, rationale, reasoning skills and time to complete. Accuracy, rationale and reasoning were scored on a 6 point rating scale (zero to five) whereas time was scored in total minutes. All four measures were converted to standard scores. Higher scores on accuracy, rationale and reasoning denote better performance whereas, higher scores on timing denotes a compromised performance. Participants also completed four subtests of the Delis-Kaplan executive function system (DKEFS) (Delis et al. 2001) (a) trail making test (b) verbal fluency (c) color-word interference test and (d) tower test.

The Trail Making Test of the DKEFS is designed to isolate set-shifting from skills such as letter sequencing and visual scanning. The test accomplishes this by including four baseline conditions (Visual Scanning, Number Sequencing, Letter Sequencing, and Motor Speed) and by placing equal numbers of stimuli in the three sequencing conditions (Yochim et al. 2007). It involves a series of five conditions: visual scanning; number sequencing; letter sequencing; number-letter switching; and motor speed. In all five conditions, the stimuli were spread over an $11 \times 17$ inch area, which provided longer trails and more interference stimuli than the traditional TMT (Delis et al. 2001). In the Visual Scanning condition, participants crossed out all the $3 \mathrm{~s}$ that appeared on the response sheet. In the Number Sequencing condition, participants drew a line connecting the numbers 1-16 in order; distractor letters appear on the same page. The Letter Sequencing condition required participants to connect the letters $\mathrm{A}$ through $\mathrm{P}$, with distractor numbers present on the page. In the Number-Letter Switching condition, participants 
switched back and forth between connecting numbers and letters (i.e., 1, A, 2, B, etc., to 16, P). Last, a Motor Speed condition was administered in which participants traced over a dotted line connecting circles on the page as quickly as possible, in order to gauge their motor drawing speed. Each condition was preceded by a short practice trial. In all conditions, participants were told to work as quickly and as accurately as possible. In all but the visual scanning condition, the examiner corrected mistakes by placing an " $\mathrm{X}$ " over a wrong connection, and participants were asked to continue from the last correct connection. The stopwatch remains running during such corrections (Yochim et al. 2007). Results for the trail making test are reported as number of seconds required to complete the task, therefore, higher scores reveal greater time needed to complete the test. Lower scores denote more compromised performance.

The D-KEFS verbal fluency test consists of three tasks: letter naming (naming as many words as possible that started with the letters $F, A$ and $S$ without repetition of sequences e.g. take, takes, taking), categorical naming (name as many animals and boys' names) and category switching (switching back and forth between naming fruits and furniture). Participants were given $60 \mathrm{~s}$ to verbally generate items in each condition and responses were recorded on paper by the examiner. Verbal fluency rates were based on the number of correct items produced in each task. Items were counted as correct if they met the constraints of the condition and were not repeated. Letter fluency scores were based on the average number of items generated across the three letter conditions. Category scores were the average number of items generated in the two categories. Switch scores were based on the correct number of items generated by correct switching between the two categories (fruits and furniture). Higher scores denote better performance.

The D-KEFS color-word interference test (Delis et al. 2001) is a version of the Stroop test (Stroop 1935) that measures inhibition of verbal responses through naming dissonant ink colors. This test presents interference in the form of competing responses in which a participant must attend to the task. The D-KEFS version contains four conditions which increase in complexity: basic color naming, word reading, inhibition and inhibition/switching. These conditions were assessed across three tasks. The Word page included color words printed in black ink and the participant read the word, the Color page included 'Xs' printed in color and the participant named the color, and Color-Word page includes color words in mismatching ink colors and the participant was required to named the color of the ink rather than reading the printed word. Raw scores are obtained for each page and include the number of items read/named in $45 \mathrm{~s}$. An Interference score provided an objective measure of inhibition, cognitive flexibility, creativity, and reaction to cognitive pressures (Lippa and Davis 2010; Shunk et al. 2006). Higher scores denote worse performance on this test.

The DKEFS tower test is a test of planning and problem solving abilities. Participants were asked to construct towers of discs on a set of pegs corresponding to a model. Raw scores were reported as an achievement score reflecting the participant's ability to use the fewest possible moves to achieve the tower depicted in the model. Lower scores denote worse performance. These subtests were chosen for administration because they assess vital executive functions including flexibility 
of thinking, inhibition, problem solving, planning, impulse control, concept formation, abstract thinking, and creativity in verbal and spatial modalities.

\section{Results}

Results of descriptive data for the PPVT-IV and the AICS scores for participants in both groups including mean standard scores for the PPVT-IV measures, mean individualism and collectivism scores for the AICS and their respective standard deviation and minimum-maximum score are presented in Table 2. No significant differences were found between the Easterners and Westerners on their receptive language vocabulary, $t(40)=-1.920, p=0.062$, education $t(40)=-1.659$, $p=0.105$, age $t(40)=-0.509, p=0.614$ or gender $\chi^{2}(1, N=42)=3.04$, $p=0.64$ suggesting that these variables had no influence on the current findings.

\section{Auckland individualism-collectivism scale}

Mean scores for the current samples are presented on Table 2. Multivariate ANOVA was used to compare the means of the Eastern and Western groups for their individualism-collectivism scores obtained through the AICS to gain insight into the individualistic and/or collectivistic nature of the groups. Collectivism scores and Individualism scores were the two dependent variables that were considered with Group being the fixed factor. Between-subject test results indicated that there was a significant difference between the two groups relative to their differences in individualism and collectivism $F(1,40)=7.542, p=0.009)$. On further analysis, simple contrasts revealed that Eastern participants showed significantly higher means for Collectivism than Westerners (contrast estimate $=0.506, p=0.009$ ). However, there was no significant difference in means between the two groups on Individualism scores (contrast estimate $=-0.042, p=0.812$ ). Figure 1 provides a graphic display for these findings on the Eastern and Western groups for Collectivism and Individualism scores.

Functional assessment of verbal reasoning and executive strategies

Participant scores on the four measures obtained through the FAVRES are presented in Table 3. Standard scores for measures of response accuracy and reasoning rationale for completion of the executive functioning tasks were obtained. In

Table 2 Descriptive statistics for PPVT-4 scores and AICS scores for participants of Eastern and Western cultures

\begin{tabular}{|c|c|c|c|c|c|c|c|c|c|}
\hline & \multirow{2}{*}{\multicolumn{3}{|c|}{ PPVT-4 }} & \multicolumn{6}{|l|}{ AICS } \\
\hline & & & & \multicolumn{3}{|c|}{ Individualism score } & \multicolumn{3}{|c|}{ Collectivism score } \\
\hline & Mean & SD & Min-max & Mean & $\mathrm{SD}$ & Min-max & Mean & SD & $\operatorname{Min}-\max$ \\
\hline Easterners & 103.95 & 4.07 & $97-110$ & 4.46 & 0.613 & $3.06-5.30$ & 4.35 & 0.611 & $3.10-5.45$ \\
\hline Westerners & 108.86 & 10.5 & $97-136$ & 4.50 & 0.518 & $3.26-5.26$ & 3.84 & 0.582 & $2.90-5.10$ \\
\hline
\end{tabular}




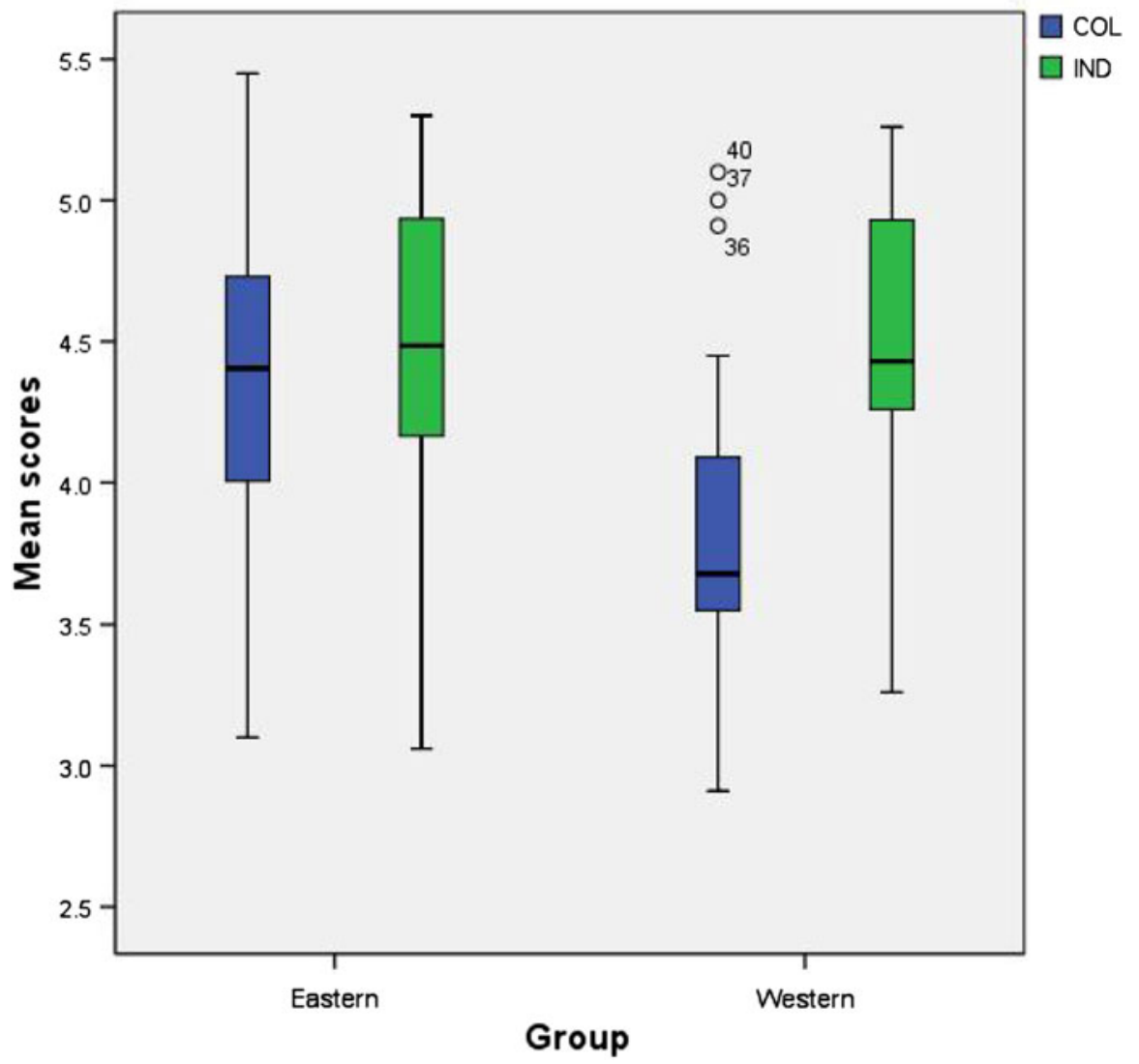

Fig. 1 Side-by-side boxplot for Eastern and Western groups comparing mean scores of Individualism and Collectivism

addition, measures of total time it took to complete the tasks as well as the reasoning sub-skills (which include getting the facts, eliminating irrelevant information, weighing facts, creative flexibility, generating ideas and predicting consequences) were collected using the FAVRES. Independent sample t-tests conducted on these data to compare mean performance of Eastern and Western groups on verbal reasoning skills revealed significant differences between the Eastern and Western groups on measures of time $t(40)=-5.853, p<0.001$ and reasoning scores $t(40)=3.502, p<0.001$ indicating that Western participants completed the four tasks on the FAVRES faster and demonstrated higher scores on the reasoning subtests.

Delis-Kaplan executive functioning system

Results from the four subtests of the DKEFS are presented in Tables 4 (trail making), 5 (verbal fluency), and 6 (color-word interference and tower test). 


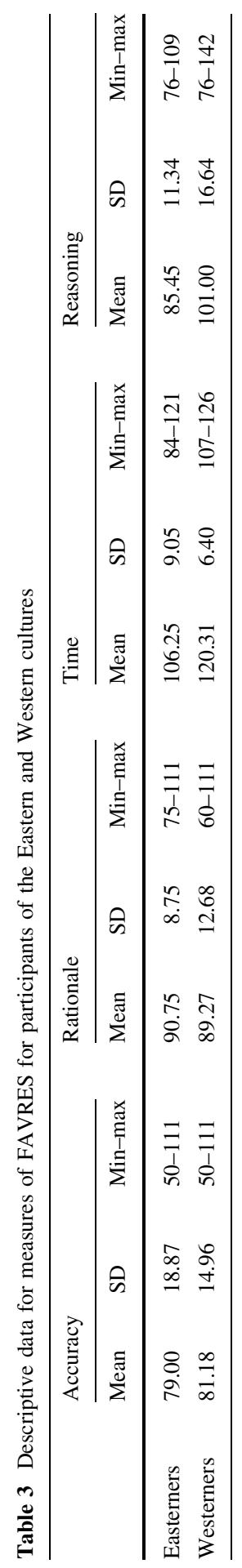







Table 5 Descriptive data for measures of DKEFS—verbal fluency subtest for participants of the Eastern and Western cultures

\begin{tabular}{|c|c|c|c|c|c|c|c|c|c|c|c|c|}
\hline & \multicolumn{3}{|c|}{ Letter fluency } & \multicolumn{3}{|c|}{ Category fluency } & \multicolumn{3}{|c|}{ Category switching } & \multicolumn{3}{|c|}{$\begin{array}{l}\text { Category switching } \\
\text { accuracy }\end{array}$} \\
\hline & Mean & SD & $\begin{array}{l}\text { Min- } \\
\max \end{array}$ & Mean & SD & $\begin{array}{l}\text { Min- } \\
\max \end{array}$ & Mean & SD & $\begin{array}{l}\text { Min- } \\
\max \end{array}$ & Mean & $\mathrm{SD}$ & $\begin{array}{l}\text { Min- } \\
\max \end{array}$ \\
\hline East & 12.50 & 2.68 & 9-19 & 13.95 & 3.15 & $8-19$ & 10.65 & 3.52 & $5-16$ & 4.80 & 1.54 & $2-7$ \\
\hline Westerners & 13.45 & 2.95 & $8-19$ & 15.04 & 3.07 & $8-19$ & 13.82 & 3.00 & $9-18$ & 6.10 & 1.26 & $4-8$ \\
\hline
\end{tabular}

Independent sample $\mathrm{t}$ tests conducted to compare mean performance of Eastern and Western groups on these executive functioning skills revealed Western participants demonstrated significantly higher categorical switching capabilities $t(40)=$ $-3.143, p=0.003$ and category switching accuracy $t(40)=-2.973, p=0.005$ on the Verbal Fluency subtest when compared to their Eastern counterparts. In comparison, the Eastern participants scored significantly higher than the Western participants on all tasks of the Trail Making subtest on the DKEFS. These tasks included visual scanning $t(40)=2.970, \quad p=0.005$, number sequencing $t(40)=3.074, p=0.004$, letter sequencing $t(40)=-3.057, p=0.004$, number-letter switching $t(40)=-2.940, p=0.005$ and the motor speed task $t(40)=-3.330, p=0.002$. Their combined number sequencing and letter sequencing scores also were found to be significantly different $t(40)=-3.634$, $p<0.001$.

\section{Discussion}

The study was proposed to gather initial data on how Eastern and Western cultures differ on cognitive processing specific to verbal reasoning, executive functioning and complex cognitive-communicative skills. It approached the culture-cognition paradigm from an observational perspective, gathering preliminary information regarding executive functioning. Research in cultural psychology has consistently identified different patterns of thinking and perception in different societies, with some cultures, typically Western culture, demonstrating a more analytic pattern and Eastern cultures a more holistic pattern. Analytic cognition characterized by taxonomic and rule-based categorization of objects, a narrow focus in visual attention, dispositional bias in causal attribution, and the use of formal logic in reasoning is typically evident in the Western population ( $\mathrm{Ji}$ et al. 2000). In contrast, holistic cognition is characterized by thematic and similarity-based categorization of objects; this includes maintaining a focus on contextual information and relationships in visual attention, an emphasis on situational causes in attribution, and dialecticism (Nisbett et al. 2001). Although these findings have been gleaned through research in social psychology, their implications for cognitive research are also insightful. These generic concepts of analytical and holistic cognition relate to 


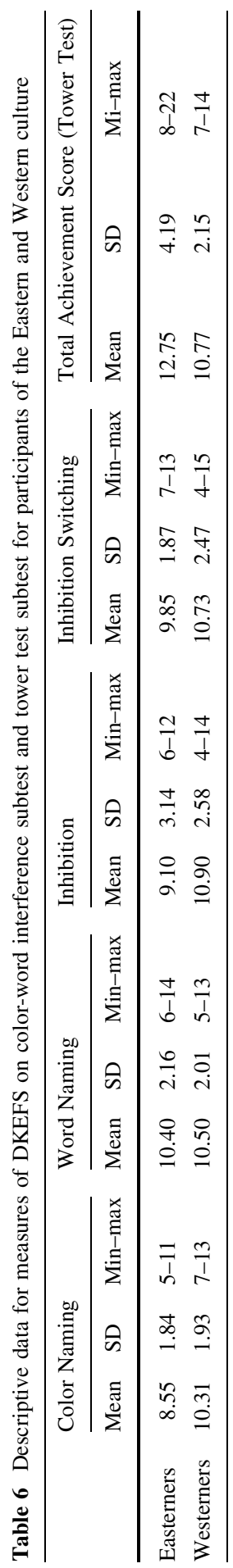


the intricate network of memory, attentional, and executive functioning systems. The findings of this study are consistent with those pertinent to memory, attention and language acquisition when considering cultural influences.

\section{Comparing Western and Eastern cultures on the AICS}

The Eastern culture was represented entirely by individuals from India making this is one of the first studies to compare Indian culture (as a part of the East Asian cultural system) to the Western culture. India (and its culture) has evolved as a collectivistic society through its centuries old traditions primarily due to linguistic, economical, religious and political diversity (Sinha and Kumar 2004). The purpose of administering the AICS was to provide evidence of collectivistic qualities in Eastern (Indian) participants as compared to the Westerners. The two groups demonstrated significant difference on Collectivism scores with Easterners showing higher means indicating presence of higher collectivistic qualities than Westerners. These differences were not evident on mean scores of Individualism because even though Indians are collectivists, they also have a well-defined sense of self including highly individualistic thoughts, self-serving interests and desire to achieve individual distinctions in society (Roland 1988; Sinha and Kumar 2004). These findings provide stronger basis to compare the two groups on executive functioning skills based on cultural differences.

\section{Comparing Western and Eastern cultures on the FAVRES}

Significant differences between the two groups on time and reasoning sub-skills were found relative to the FAVRES subtests. It is critical to note that both Eastern and Western groups did not differ significantly on accuracy means and rationale scores on the FAVRES tasks, (which included tasks such as planning an event, scheduling, making a decision, and building a case). These results suggest that although there are identifiable differences in the way individuals of these two cultures process information, their explicit cognitive processes guide them correctly toward completion of the task. The two critical variables that separated the groups were timing of task completion and reasoning skills. Western participants excelled at both speed of task completion and higher scores on reasoning sub-skills. This cultural difference may be explained relative to how the presented information (in this case written) is processed and executed differently by the two groups. Through analytical processing, Western participants appear to filter out irrelevant information presented in the task. Thus, their attention was directed towards completion of the problem by focusing on target response. They objectively refined the abundance of information presented in the tasks to converge on the target response thereby allowing them to complete the written tasks with increased speed. Conversely, the Eastern individuals appeared to focus on all the information that was presented and tried to identify contextual references to better solve the underlying problem. This holistic approach appears to build on processing time, thus causing performance delay in completion of the executive functioning task. It is important to note that this delay could very well be the result of bilingualism or in some cases 
multilingualism that is common in the Indian population. Research has shown that there are negative influences of bilingualism on verbal knowledge and skills. Specifically, bilingualism often yields smaller vocabularies and less-rapid access to lexical items. This is easily outweighed by evidence supporting a range of advantages in development, efficiency, and maintenance of executive functions (Bialystok and Craik 2010). However, the results did not reveal a significant difference in receptive vocabulary between the two groups. This may be because English was the medium of instruction for all Eastern participants during their educational years (approximately 16 years). However, this question does carry potential for further research. Furthermore, more extensive language assessment is needed to determine if there are other differences in language proficiency such as reading speed which may influence executive functioning in these populations.

\section{Comparing Western and Eastern cultures on the DKEFS}

Westerners demonstrated higher scores on the category switching task of the verbal fluency subtest on the DKEFS. The category switching task involves participants switching between two unrelated categories of fruits and furniture. Western participants were able to switch between the two categories with greater frequency as compared to Easterners. These findings are consistent with those of Chiu (1972) who found that American children preferred to group objects because they belonged to the same classification term ("adults", "tools", "animals") more effectively as compared to Asian children who preferred to group objects based on their similarities and relationships. Categories are primarily denoted by nouns and Western culture emphasizes learning of nouns through childhood developmental stages. Another possible reason for Easterners' lower performance may be because verbs are highly reactive i.e. their ability to remember categories with reference to verbs or context is than with nouns which might hinder their ability to recall two independent categories with greater fluency. Additionally, Nisbett and Norenzayan (2002) and Tardif (1996) found that East Asian children learn verbs at a significantly faster rate than nouns as verbs are more salient in East Asian languages.

Easterners showed superior performance on all tasks of the Trail Making Test (visual scanning, number sequencing, letter sequencing, number-letter switching and motor speed), a neuropsychological test of assessing visual attention and task switching. These findings are consistent with cultural studies conducted by Ji et al. (2000) who found that East Asian perception seems to be holistic not only with regards to a single stimulus but with respect to perception of the visual field as a whole. Through eye-gaze experiments, Chua et al. (2005a, b) found that eye movements can differ as a function of culture in which Easterners and Westerners have been found to allocate attention resources differently when viewing a scene/ picture. They found that Westerners direct their attention primarily to the foreground and focus on details whereas Easterners are attentive to the background and are more holistic in their attentional approach. This cultural variability may illustrate the difference in visual attention and task switching scores in the current investigation in which Easterners were able to complete the visuo-motor tasks faster 
as a result of their aptitude to maintain a comprehensive perspective of the visual surface.

\section{Limitations and future scope}

More extensive evaluation of language skills among participants of two groups may be recommended. The Peabody Picture Vocabulary Test-IV provides an objective measure of spoken receptive language vocabulary for Standard American English. However, assessment of other language skills, such as expressive vocabulary, auditory and visual comprehension, reading speed and language samples of both spoken and written expression may provide a broader perspective on how language and culture can affect executive functioning skills and strengthen interpretation and conclusions relative to experimental findings. With increased linguistic information the suggested next step in this line of research is to compare, contrast and utilize existing cognitive test batteries on individuals of other cultures to identify if these tools are culturally sensitive. As there is growing number of multicultural individuals in the United States requiring speech and language therapeutic intervention, it is essential to take into consideration the patient's cultural background in the development of diagnostic tests and therapy strategies. Applied research is warranted to validate the role of culture in cognitive processing so as to help speech-language professionals in development of new assessment tools and more appropriate use of existing test batteries with multicultural populations.

Another area requiring additional attention is the effect of bilingualism in executive functioning. Asian cultures are traditionally bilingual (or even multilingual) in nature. As mentioned, with the growing number of people from Eastern cultures learning and using English in everyday life, understanding how bilingualism affects the exchange of information and its impact on memory, attention, decision-making and executive functioning skills becomes critical. Knowledge of how individuals from monolingual cultures and bi/multilingual cultures perceive and process written and/or verbal language information may help understand how linguistic perception may affect higher level of abstraction, categorization, inference, reasoning and other skills that with executive functioning.

\section{Conclusion}

There is growing evidence that perception and processing of information may be influenced by culture. In the current investigation, researchers attempted to explore the influence of cultural background on various components of executive functioning. Culture appears to have a global impact on the manner in which humans process information and make executive decisions. The interplay of language and other cognitive processes is already receiving attention in cognitive, developmental, and linguistic research. Such research is valuable to clinicians in a world where opportunities to assess and treat multicultural patients are increasing. Thus, it is imperative that further research be conducted to identify the extent to which perceptual and linguistic processes are affected by culture. This type of 
research may provide useful foundations for designing culturally sensitive assessment tools and treatment strategies for obtaining more authentic representations of a patient's executive functioning skills as well as other cognitive processes.

\section{Appendix}

\section{Auckland Individualism-Collectivism Scale}

\section{Auckland Individualism Collectivism Scale}

The purpose of this questionnaire is to find out how you think or behave in regard to yourself and to groups to which you belong. Please read the following questions and answer each question by indicating how often you would think or behave as described in each of the following items.

Never $=1$ Always $=6$

\begin{tabular}{|c|c|c|c|c|c|c|}
\hline & 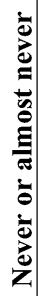 & 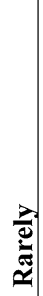 & 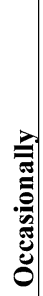 & 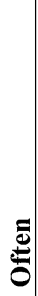 & 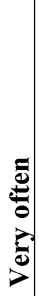 &  \\
\hline 1. I define myself as a competitive person. & & & & & & \\
\hline 2. I enjoy being unique and different from others. & & & & & & \\
\hline $\begin{array}{l}\text { 3. Before I make a major decision I seek advice from people } \\
\text { close to me. }\end{array}$ & & & & & & \\
\hline $\begin{array}{l}\text { 4. Even when I strongly disagree with my group members, I } \\
\text { avoid an argument. }\end{array}$ & & & & & & \\
\hline 5. I consult with superiors on work related matters. & & & & & & \\
\hline 6. I believe that competition is a law of nature. & & & & & & \\
\hline $\begin{array}{l}\text { 7. I prefer competitive rather than non-competitive recreatio } \\
\text { activities }\end{array}$ & & & & & & \\
\hline 8. Before taking a major trip I consult with my friends & & & & & & \\
\hline 9. I sacrifice my self-interest for the benefit of my group & & & & & & \\
\hline $\begin{array}{l}\text { 10. I consider my friends' opinions before taking important } \\
\text { actions }\end{array}$ & & & & & & \\
\hline 11. I like to be accurate when I communicate & & & & & & \\
\hline 12. I consider myself as a unique person separate from others & & & & & & \\
\hline $\begin{array}{l}\text { 13. It is important to consult close friends and get their ideas } \\
\text { before making a decision }\end{array}$ & & & & & & \\
\hline
\end{tabular}




\begin{tabular}{|c|c|c|c|c|c|c|}
\hline & 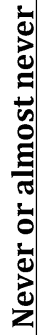 & $\frac{7}{0}$ & 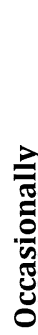 & & : & $\frac{\infty}{\zeta}$ \\
\hline $\begin{array}{l}\text { 14. Without competition, I believe, it is not possible to have a } \\
\text { good society }\end{array}$ & & & & & & \\
\hline $\begin{array}{l}\text { 15. I ask the advice of my friends before making career relate } \\
\text { decisions }\end{array}$ & & & & & & \\
\hline $\begin{array}{l}\text { 16. I prefer using indirect language rather than upsetting my } \\
\text { friends by telling them directly what they might not like to } \\
\text { hear }\end{array}$ & & & & & & \\
\hline 17. It is important for me to act as an independent person & & & & & & \\
\hline 18. I discuss job related problems with my parents/partner & & & & & & \\
\hline 19. I take responsibility for my own actions & & & & & & \\
\hline 20. I do not reveal my thoughts when it might initiate a disput & & & & & & \\
\hline $\begin{array}{l}\text { 21. I try to achieve better grades (results) than my peers (co- } \\
\text { workers) }\end{array}$ & & & & & & \\
\hline 22. My personal identity independent is very important to me & & & & & & \\
\hline $\begin{array}{l}\text { 23. I enjoy working in situations involving competition with } \\
\text { others }\end{array}$ & & & & & & \\
\hline 24. I consult my family before making an important decision & & & & & & \\
\hline 25. Winning is very important to me & & & & & & \\
\hline 26. I see myself as "my own person" & & & & & & \\
\hline
\end{tabular}

Gender: [ ] Male [ ] Female

Age : [ ] 15-20 [ ] 21-25 [ ] 26-30 [ ] 31-35 [ ] 36-40

Ethnicity: [ ] Asian

[] American

\section{References}

Ardila, A. (2008). On the evolutionary origins of executive functions. Brain and Cognition, 68, 92-99. Bechara, A., Damasio, H., \& Damasio, A. R. (2000). Emotion, decision making and the orbitofrontal cortex. Cerebral Cortex, 10, 295-307.

Bialystok, E., \& Craik, F. (2010). Cognitive and linguistic processing in the bilingual mind. Current Directions in Psychological Science, 19, 19-23.

Braver, T. \& Barch, D. (2002). A theory of cognitive control, aging cognition, and neuromodulation. Neuroscience \& Biobehavioral Reviews, 26, 809-817. 
Chiao, J., Harada, T., Komeda, H., Li, Z., Mano, Y., Saito, D., et al. (2009). Neural basis of individualistic and collectivistic views of self. Human Brain Mapping, 30, 2813-2820.

Chiu, L. H. (1972). A cross-cultural comparison of cognitive styles in Chinese and American children. International Journal of Psychology, 8, 235-242.

Chua, H. F., Boland, J. E., \& Nisbett, R. (2005a). Cultural variation in eye movements during scene perception. Proceedings of the National Academy of Sciences of the United States of America, 102, 629-633.

Chua, H. F., Liu, J., \& Nisbett, R. E. (2005b). Culture and diverging views of social events. Personality and Social Psychology Bulletin, 31, 925-934.

Delis, D. C., Kaplan, E., \& Kramer, J. H. (2001). Delis-Kaplan executive function system (DKEFS). San Antonio, TX: The Psychological Corporation.

Duffy, S., \& Kitayama, S. (2007). Mnemonic context effect in two cultures: attention to memory representations? Cognitive Science, 31, 1009-1020.

Dunn, L., \& Dunn, D. (2007). Peabody picture vocabulary test (4th ed.). Minneapolis, MN: Pearson Inc.

Goh, J. O., \& Park, D. C. (2005). Culture sculpts the perceptual brain. Progress in Brain Research, 178, 95-111.

Gutchess, A. H., Yoon, C., Luo, T., et al. (2006). Categorical organization in free recall across culture and age. Gerontology, 52, 314-323.

Hedden, T., Ketay, S., Aron, A., Markus, H. R., \& Gabrieli, J. (2008). Cultural influences on neural substrates of attentional control. Psychological Science, 19, 12-17.

Ji, L., Peng, K., \& Nisbett, R. E. (2000). Culture, control, and perception of relationships in the environment. Journal of Personality and Social Psychology, 78, 943-955.

Lippa, S., \& Davis, R. (2010). Inhibition/switching is not necessarily harder than inhibition: An analysis of the D-KEFS color-word interference test. Archives of Clinical Neuropsychology, 25, 146-152.

MacDonald, S., \& Johnson, C. (2005). Functional assessment of verbal reasoning and executive strategies. Ontario: CCD Publishing.

Markus, H. R., \& Kitayama, S. (1991). Culture and the self: implications for cognition, emotion and motivation. Psychological Review, 98, 224-253.

Masuda, T., \& Nisbett, R. E. (2001). Attending holistically versus analytically: Comparing the context sensitivity of Japanese and Americans. Journal of Personality and Social Psychology, 81, 922-934.

Nisbett, R. E. (2003). The geography of thought: How Asians and Westerners think differently and why. New York: The Free Press.

Nisbett, R. \& Norenzayan, A. (2002). Culture and cognition. In H. Pashler \& D. Medin (Eds.), Stevens' handbook of experimental psychology: Cognition (pp. 561-597). New York, NY: Wiley.

Nisbett, R. E., Peng, K., Choi, I., \& Norenzayan, A. (2001). Culture and systems of thought: Holistic versus analytic cognition. Psychological Review, 108, 291-310.

Ohbuchi, K., Fukushima, O., \& Tedeschi, J. (1999). Cultural values in conflict management: Goal orientation, goal attainment, and tactical decision. Journal of Cross-Cultural Psychology, 30, 51-71.

Oyserman, D., \& Lee, S. W. (2008). Does culture influence what and how we think? Effects of priming individualism and collectivism. Psychological Bulletin, 134, 311-342.

Park, D. C., \& Gutchess, A. H. (2002). Aging, cognition and culture: a neuroscientific perspective. Neuroscience and Behavioral Reviews, 26, 859-867.

Roland, A. (1988). In search of self in India and Japan: Towards a cross-cultural psychology. Princeton, NJ: Princeton University Press.

Shulruf, B., Hattie, J., \& Dixon, R. (2007). Development of a new measurement tool for individualism and collectivism. Journal of Psychoeducational Assessment, 25, 385-401.

Shunk, A., Davis, A., \& Dean, R. (2006). TEST REVIEW: Dean C. Delis, Edith Kaplan \& Joel H. Kramer, Delis Kaplan executive function system (D-KEFS), The Psychological Corporation, San Antonio, TX, 2001. Applied Neuropsychology, 13, 275-277.

Sinha, J., \& Kumar, R. (2004). Methodology for understanding Indian culture. The Copenhagen Journal of Asian Studies, 19, 89-104.

Stroop, J. (1935). Studies of interference in serial verbal reactions. Journal of experimental psychology, $18,643-662$.

Tardif, T. (1996). Nouns are not always learned before verbs: evidence from Mandarin speakers early vocabularies. Developmental Psychology, 32, 492-504.

Triandis, H. C. (1989). The self and social behavior in differing cultural contexts. Pyschological Review, 96, 506-520.

Triandis, H. C. (1995). Individualism and collectivism (pp. 19-38). Boulder, CO: Westview Press. 
Triandis, H. C. (1996). The psychological measurement of cultural syndromes. American Psychologist, $51,407-415$.

Triandis, H. C. (2001). Individualism-collectivism and personality. Journal of Personality, 69, 907-924.

Unsworth, S. J., Sears, C. R., \& Pexman, P. M. (2005). Cultural influences on categorization processes. Journal of Cross-Cultural Psychology, 36, 662-688.

Yochim, B., Baldo, J., Nelson, A., Delis, D., Arbuthnott, K., \& Frank, J. (2007). D-KEFS trail making test performance in patients with lateral prefrontal cortex lesions. Journal of the International Neuropsychological Society, 13, 704-709.

Yoon, C., Feinberg, F., Hu, P., et al. (2004). Category norms as a function of culture and age: Comparisons of item responses to 105 categories by American and Chinese adults. Psychology and Aging, 19, 379-393.

Zhu, Y., Zhang, L., Fan, J., \& Han, S. (2007). Neural basis of cultural influence on self representation. Neuroimage, 34, 1310-1316. 